\title{
Carbon monoxide mixing ratios over Oklahoma between 2002 and 2009 retrieved from Atmospheric Emitted Radiance Interferometer spectra
}

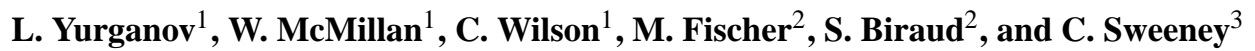 \\ ${ }^{1}$ Joint Center for Earth System Technology, University of Maryland Baltimore County, Baltimore, MD, USA \\ ${ }^{2}$ Lawrence Berkeley National Laboratory, Berkeley, CA, USA \\ ${ }^{3}$ Global Monitoring Division, Earth Systems Research Laboratory, National Oceanic and Atmospheric Administration, \\ Boulder, CO, USA
}

Received: 7 February 2010 - Published in Atmos. Meas. Tech. Discuss.: 29 March 2010

Revised: 1 September 2010 - Accepted: 6 September 2010 - Published: 5 October 2010

\begin{abstract}
CO mixing ratios for the lowermost 2-km atmospheric layer were retrieved from downwelling infrared (IR) radiance spectra of the clear sky measured between 2002 and 2009 by a zenith-viewing Atmospheric Emitted Radiance Interferometer (AERI) deployed at the Southern Great Plains (SGP) observatory of the Atmospheric Radiation Measurements (ARM) Program near Lamont, Oklahoma. A version of a published earlier retrieval algorithm was improved and validated. Archived temperature and water vapor profiles retrieved from the same AERI spectra through automated ARM processing were used as input data for the $\mathrm{CO}$ retrievals. We found the archived water vapor profiles required additional constraint using SGP Microwave Radiometer retrievals of total precipitable water vapor. A correction for scattered solar light was developed as well. The retrieved CO was validated using simultaneous independently measured $\mathrm{CO}$ profiles from an aircraft. These tropospheric $\mathrm{CO}$ profiles were measured from the surface to altitudes of $4572 \mathrm{~m}$ a.s.l. once or twice a week between March 2006 and December 2008. The aircraft measurements were supplemented with ground-based $\mathrm{CO}$ measurements using a non-dispersive infrared gas correlation instrument at the SGP and retrievals from the Atmospheric IR Sounder (AIRS) above $5 \mathrm{~km}$ to create full tropospheric $\mathrm{CO}$ profiles. Comparison of the profiles convolved with averaging kernels to the AERI CO retrievals found a squared correlation coefficient of 0.57 , a standard deviation of $\pm 11.7 \mathrm{ppbv}$, a bias of $-16 \mathrm{ppbv}$, and a slope of
\end{abstract}

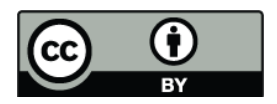

Correspondence to: L. N. Yurganov (yurganov@umbc.edu)
0.92. Averaged seasonal and diurnal cycles measured by the AERI are compared with those measured continuously in situ at the SGP in the boundary layer. Monthly mean CO values measured by the AERI between 2002 and 2009 are compared with those measured by the AIRS over North America, the Northern Hemisphere mid-latitudes, and over the tropics.

\section{Introduction}

Carbon monoxide is a by-product of any combustion, both anthropogenic and natural (e.g., wild fires), and a result of photochemical conversion from methane and other carbonaceous gases (Bergamaschi et al., 2000). Primarily, it is removed from the atmosphere through reaction with hydroxyl (OH) (Spivakovsky et al., 2000). CO is a relatively shortlived gas (life time $\sim 2$ months) conveniently measured in situ using gas-chromatography, non-dispersive infrared (IR) technique, diode lasers, open path Fourier Transform IR spectrometrs (FTIR) (Sachse et al., 1987; Jaffe et al., 1998; Goode et al, 1999; Novelli et al., 2003; Nedelec et al., 2003). Sun-viewing spectrometers supply remotely sensed CO total column amounts and some information about the vertical distributions of CO (e.g., Dianov-Klokov and Yurganov, 1981; Zander et al., 1989; Rinsland et al., 1998). Spacebased remote sensing IR spectroscopic techniques (Reichle et al., 1990; Buchwitz et al., 2004; McMillan et al., 2005; Edwards et al., 2006; Turquety et al., 2009) provide information about $\mathrm{CO}$ mixing ratios in the free troposphere. $\mathrm{CO}$ is widely used as a tracer of biomass burning (McMillan et al., 2008a, b; Edwards et al., 2004; Turquety et al., 2009) and

Published by Copernicus Publications on behalf of the European Geosciences Union. 
anthropogenic pollution (Clerbaux et al., 2008; McMillan et al., 2008a, 2009a). CO measurements are helpful for validation of Chemical Transport Models (CTMs) (Zhang et al., 2008), and as input information for source inversion models (Fisher et al., 2010; Kopacz et al., 2010).

This paper presents results of remote sensing $\mathrm{CO}$ measurements using the Atmospheric Emitted Radiance Interferometer (AERI) at the Southern Great Plains (SGP) site of the United States Department of Energy (DOE) Atmospheric Radiation Measurement (ARM) Program. As stated at its official web site (http://newdesign.arm.gov/about/), "ARM is a multi-laboratory, interagency program, and is a key contributor to national and international research efforts related to global climate change. A primary objective of the program is improved scientific understanding of the fundamental physics related to interactions between clouds and radiative feedback processes in the atmosphere. ARM focuses on obtaining continuous field measurements and providing data products that promote the advancement of climate models".

A retrieval technique used in this paper is an improved version of that described by Wang et al. (1999) and He et al. (2001). They reported the first results of CO retrievals from the AERI SGP spectra for a short period between 2 and 4 March 1998 using a code specified here as version 1 (v1). In the present paper, the $\mathrm{v} 1$ retrieval algorithm was modified and is designated now as version 2 (v2). Here, we present validation and analysis of $\mathrm{CO}$ retrievals from the SGP AERI from 2002 through 2009. A more comprehensive analysis of this data set, possibly extended back to 1997 , will be the subject of future publications.

The SGP AERI CO retrievals between February 2006 and December 2008 are validated using three independent, simultaneous, and collocated sets of CO data: (i) quasicontinuous in situ measurements of $\mathrm{CO}$ mixing ratios from a $60 \mathrm{~m}$ tower (Biraud et al., 2007), (ii) in situ CO profiles measured from aircraft between $83 \mathrm{~m}$ and $4572 \mathrm{~m}$ above the ground (Sweeney at al., 2010), and (iii) CO profiles retrieved from a space-borne AIRS sounder for altitudes above $5 \mathrm{~km}$ (McMillan et al., 2009b). The 7.5-year period of the AERI CO retrievals, 1 January 2002 through September 2009, is analyzed and interpreted in terms of changes in fossil fuel and biomass burning emissions.

\section{Location, instrument, and retrieval procedure}

The SGP site $\left(36^{\circ} 36^{\prime} 18.0^{\prime \prime} \mathrm{N}, 97^{\circ} 29^{\prime} 6.0^{\prime \prime} \mathrm{W}\right)$ is located in northern Oklahoma, southeast of the town of Lamont. Its central facility is surrounded by cattle pasture and wheat fields. "The instruments throughout the site automatically collect data on surface and atmospheric properties, routinely providing data to the Site Data System, which is linked by high-speed communications to the ARM Archive and Data Center". (http://newdesign.arm.gov/sites/sgp.stm). The collected data and derived products are archived and publicle

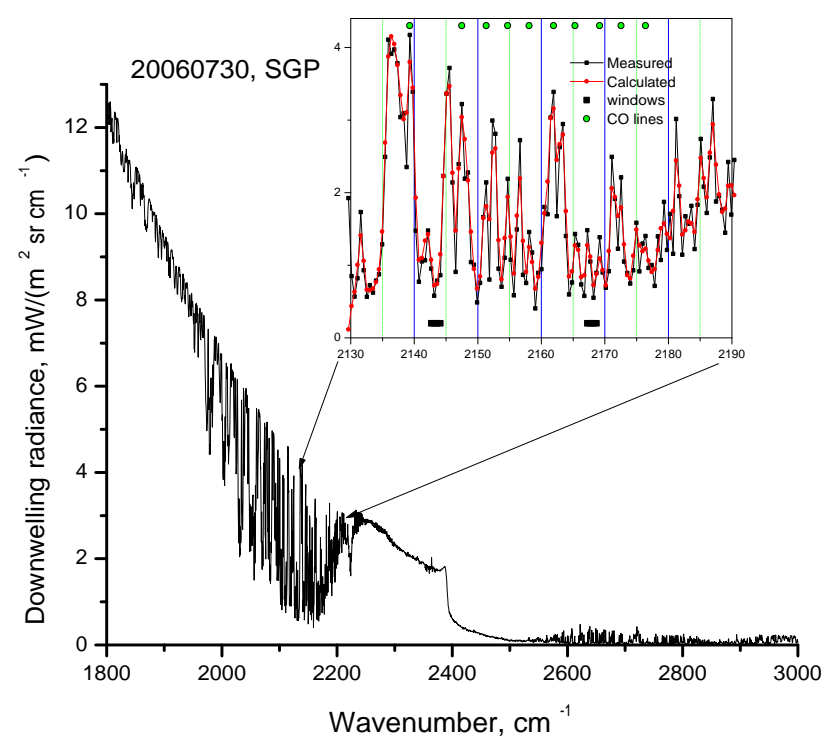

Fig. 1. An example spectrum of atmospheric zenith-sky radiances measured by the SGP AERI on 30 July 2006 at 12:45 UTC together with that calculated for the constant $\mathrm{CO}$ profile with mixing ratio $78.4 \mathrm{ppb}$ (inserted). Green circles indicate locations of $\mathrm{CO}$ lines. Black bars correspond to locations of transparent windows used for estimates of scattered solar radiance.

available online (http://www.archive.arm.gov). The AERI measures the downwelling absolute infrared spectral radiance (in watts per square meter per steradian per wavenumber) emitted by the sky directly above the instrument (Knuteson et al., 2004a, b). The AERI spectra can be used for investigation of boundary layer (BL) temperature and water vapor distributions (Feltz et al., 1998; Smith et al., 1999; Turner et al., 2000), cloud properties (Collard et al., 1995; DeSlover et al., 1999; Turner et al., 2003), carbon monoxide retrievals (He et al., 2001), and other applications (Minnett et al., 2001; Nalli et al., 2008). The AERI measurements cover the spectral range from 520 to $3300 \mathrm{~cm}^{-1}(3-19.2 \mu \mathrm{m})$ with an unapodized spectral resolution of $1.0 \mathrm{~cm}^{-1}(1 \mathrm{~cm}$ optical path difference). The instrument field-of-view is $1.3^{\circ}$. In normal operation, a calibrated sky radiance spectrum (3-min average) is produced approximately every $8 \mathrm{~min}$ utilizing views of two precisely monitored high emissivity calibration blackbodies (Knuteson et al., 2004a, b).

A sample spectrum of atmospheric zenith-sky radiances measured by the SGP AERI on 30 July 2006 is plotted in Fig. 1. One line of the P-branch and nine lines of the Rbranch of the CO 1-0 fundamental vibration-rotation band appear as spikes in the radiance spectrum at the frequencies indicated by the green circles. Other spikes in the inset spectrum arise from water vapor emission. Two transparent intervals (windows) represent spectral intervals with minimal contribution from atmospheric gases. However, radiation emitted and scattered by aerosols, thin clouds, and 
other sources influence measurements in the spectral windows. For example, during the daytime, a tail of the solar radiation scattered by aerosols and thin clouds often shows up between 2500 and $3000 \mathrm{~cm}^{-1}$. The contribution of this solar radiance for the interval between 2130 and $2190 \mathrm{~cm}^{-1}$ should be small, but it is variable both diurnally and day-today due to aerosol scattering. This scattered sunlight depends on the solar zenith angle, aerosol abundance, and the presence of thin clouds (especially Ci). Spectra for thick clouds are removed from our analysis as discussed below.

The basic AERI CO retrieval procedure was originally developed and validated for retrievals from space- and airborne IR spectra (McMillan et al., 1996, 1997, 2003) and subsequently modified for retrievals from the AERI spectra (Wang et al., 1999; He et al., 2001). It is a oneparameter (CO column) retrieval algorithm based on temperature and water vapour profiles already retrieved from other portions of the same AERI spectra and archived. Radiative transfer calculations between 2100 and $2200 \mathrm{~cm}^{-1}$ are performed using the k-Compressed Atmospheric Radiative Transfer Algorithm (kCARTA) (De Souza-Machado et al., 1997). Archived temperature and water vapor profile retrievals have been performed by automated ARM processing using standard AERI software developed by the University of Wisconsin (Feltz et al., 1998). The water vapour profiles were retrieved from the $538-588 \mathrm{~cm}^{-1}$ and $1250-1350 \mathrm{~cm}^{-1}$ spectral regions. The temperatures were determined using the lines in the $620-720 \mathrm{~cm}^{-1}$ spectral region of the $15 \mu \mathrm{m} \mathrm{CO}$ band. The Rapid Update Cycle-2 (RUC2) or Global Forecast System (GFS) were used as forward models (Feltz et al., 1998; Smith et al., 1999; Turner et al., 1999; Feltz et al., 2003).

In the $\mathrm{v} 1$ and $\mathrm{v} 2 \mathrm{CO}$ retrieval algorithms, a constant tropospheric $\mathrm{CO}$ mixing ratio profile (from $100 \mathrm{mb}$ to the surface) is perturbed from the initial value of $100 \mathrm{ppb}$ to minimize the spectral residuals due to $\mathrm{CO}$. However, the vertical sensitivity of this technique is not uniform. Figure 2 shows a representative averaging kernel for the $\mathrm{v} 2 \mathrm{CO}$ retrieval and indicates that most of the signal comes from the boundary layer. The AERI CO averaging kernels and this figure are discussed in more detail in Sect. 3.

As detailed in McMillan et al. (1997), a brightness temperature spectrum for the $\mathrm{v} 1$ algorithm is calculated for constant tropospheric $\mathrm{CO}$ mixing ratios using the best available spectral constants from the HITRAN-2004 compilation (Rothman et al., 2005) and the aforementioned AERI temperature/ $\mathrm{H}_{2} \mathrm{O}$ retrieved profiles. Then a difference (or residual) between the calculated and measured spectra is derived. As a result of the regular spacing of the CO lines, the shape of this residual at AERI's $1 \mathrm{~cm}^{-1}$ resolution is nearly sinusoidal. The amplitude of this $C O$ signal is proportional to the difference in column $\mathrm{CO}$ between the observed and calculated spectrum. Only one piece of information about $\mathrm{CO}$ (namely, air pressure-weighted mixing ratio) is retrieved from each spectrum. Utilizing a standard Fourier signal

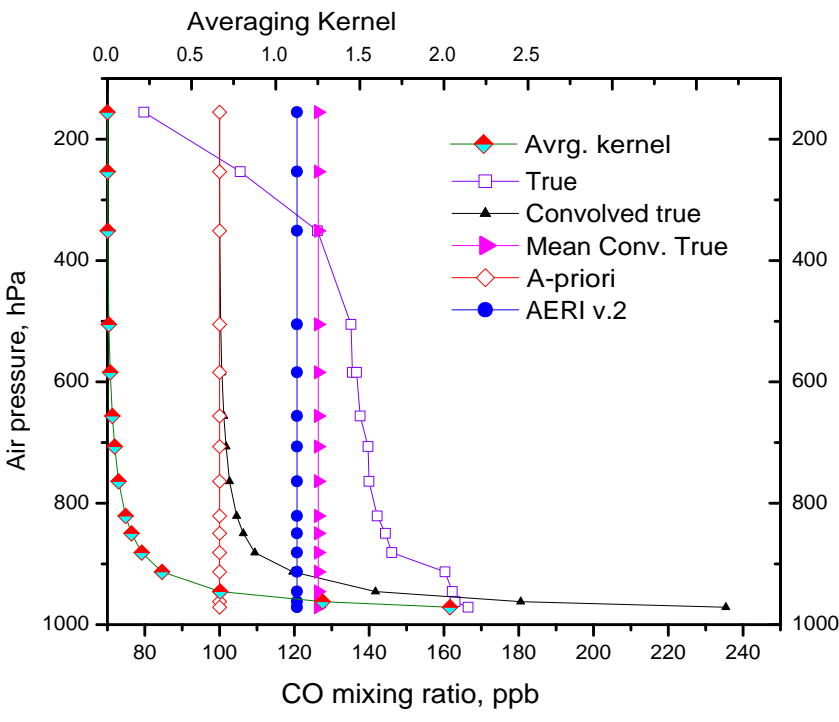

Fig. 2. A comparison of CO retrieved from the AERI spectra for 1630-1730 UTC, 27 April 2006, with the independently derived data. The composite ("true") profile consists of the in situ tower measurement, in situ aircraft data (below $600 \mathrm{hPa}$ level, from 16:36 to 18:15 UTC), and AIRS v5 L3 product for 27 April 2006, around 1900 UTC. Black triangles are for composite profile convolved with the AERI averaging kernel. Magenta triangles are used for the convolved composite profile averaged over the altitude. Also plotted are the constant $100 \mathrm{ppbv}$ a priori $\mathrm{CO}$ profile (red diamonds), the AERI v2 retrievals averaged between 16:30 and 17:30 UTC (blue circles), and the $\mathrm{CO}$ averaging kernel calculated for the given conditions.

processing technique (not to be confused with a Fourier transform spectrometric technique), called the Welch method (Candy, 1988; Fante, 1988), we can quantify the amplitude of the sinusoidal residual with a good rejection of $\mathrm{H}_{2} \mathrm{O}$ contamination. Spectral residuals are computed for constant $\mathrm{CO}$ mixing ratios of 50,100,200, and $400 \mathrm{ppbv}$ and a cubic interpolation is applied to the cross-spectral density computed via the Welch method to retrieve the best fit constant CO mixing ratio (McMillan et al., 1997). In spite of its relative simplicity, this technique ensures a good retrieval accuracy (in most cases, better than $10 \%$, see discussion below) combined with relatively fast spectra processing (1-2 min per spectrum).

The basic cloud filtering technique is described by He et al. (2001). Spectra contaminated by thick or low clouds exhibit a low brightness contrast within the $2100-2200 \mathrm{~cm}^{-1}$ spectral range. Low contrast results in lower retrieved CO. Although this spectral contrast shows some seasonality, $\mathrm{He}$ et al. (2001) found contrasts $<40 \mathrm{~K}$ between the most transparent and opaque portions of the $2100-2200 \mathrm{~cm}^{-1}$ spectral range indicate the presence of clouds. However, this filtering alone does not find all clouds. Thin clouds, especially cirrus, may display a contrast $>40 \mathrm{~K}$, yet their presence can influence the $2100-2200 \mathrm{~cm}^{-1}$ spectral region by scattering 


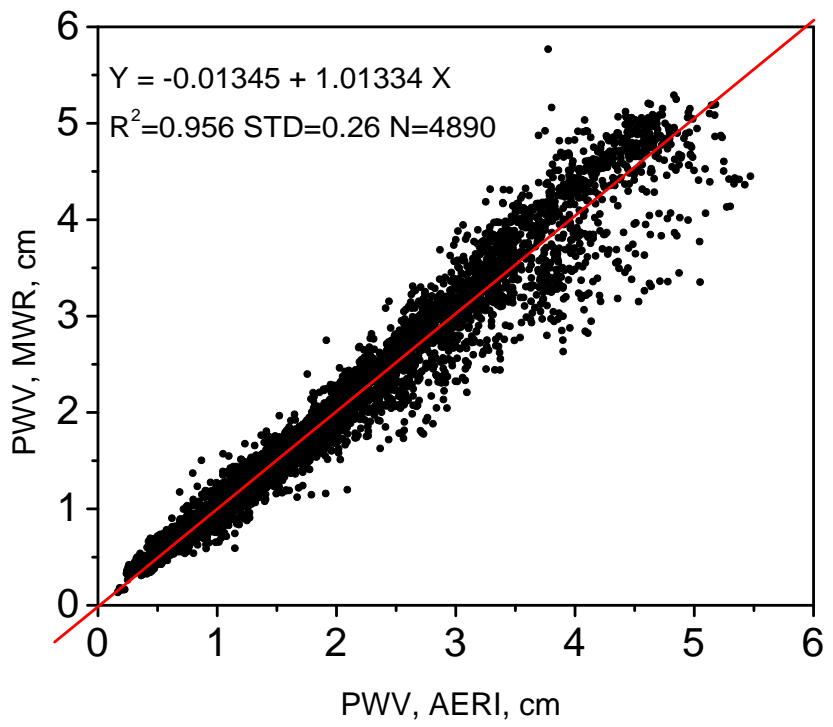

Fig. 3. Comparison of precipitable water vapor (PWV) retrieved from the AERI spectra and from MWR data during 2006. The squared correlation coefficient is 0.956 .

of solar photons during the day. The effect of these clouds can be comparable to solar scattering by aerosols. A method of correction for such cases is described below.

Ongoing research is investigating the possibility of simultaneously retrieving BL and mean free tropospheric (MFT) $\mathrm{CO}$ mixing ratios from the AERI spectra. Preliminary sensitivity studies indicate this should be possible roughly $75 \%$ of the time. In addition, work will soon start on a new fast radiative transfer algorithm to enable reprocessing of the AERI spectra for $\mathrm{CO}, \mathrm{CO}_{2}$, and $\mathrm{CH}_{4}$ retrievals. Parallel research with collaborators at the University of Wisconsin-Madison includes improvements to the AERI temperature and water vapor retrieval algorithms.

\subsection{Influence of water vapor profile errors on AERI CO retrievals}

As it is well known (see, e.g., Sussmann and Borsdorf, 2007), the $\mathrm{CO}$ fundamental band is overlapped by numerous water vapor lines. To estimate the impact of systematic precipitable water vapor (PWV) errors on retrievals of $\mathrm{CO}$ from the AERI spectra, we employed independent measurements of PWV made by the SGP microwave radiometer (MWR) (Liljegren, 1994). Turner et al. (2007) investigated the accuracy of the MWR PWV and found the disagreement with coincident scanning Raman lidar and radiosondes was well below $\pm 10 \%$. Although generally well correlated, we have found the differences between the AERI and MWR PWV can be as large as $20-40 \%$. The largest discrepancies appear for PWV $>3 \mathrm{~cm}$ (Fig. 3) where the AERI often overestimates PWV. However, we note that for PWV $<3 \mathrm{~cm}$, agreement between the AERI and MWR PWV is much better.

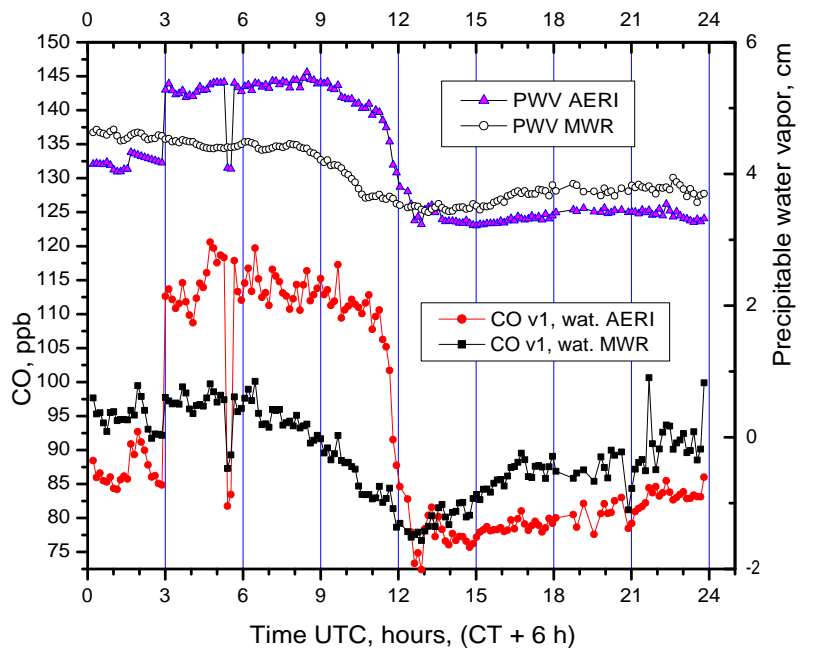

Fig. 4. An example of AERI-derived PWV compared with MWRderived PWV (top two curves). The bottom two curves are individual $\mathrm{CO}$ retrievals with input water vapor profiles from AERI spectra (red) and AERI-derived water vapor profile scaled using MWR PWV (black).

Figure 4 presents an example of the impact of PWV on CO retrievals for a humid summer day, 30 July 2006. The top panel shows PWV measured by the MWR and the AERI. AERI PWV increased instantly, from one AERI spectrum to the next, around 03:00 UTC (21:00 LT) and rapidly decreased around 12:00 UTC (06:00 LT); MWR PWV changed much more gradually. Such dramatic jumps in PWV measured by the AERI in contrast to much more gradual changes in PWV measured by the MWR allows us to assume that the MWR measurements of PWV are more precise. This can be explained by the nature of the AERI retrieval technique, which is designed for the $\mathrm{H}_{2} \mathrm{O}$ profiles. Most of the water vapor, especially for humid conditions, is concentrated in the boundary layer and large vertical gradients of the water vapor mixing ratios are difficult to estimate with the AERI spectral resolution. The bottom panel illustrates the impact of this PWV error on the retrieved CO. Variations in the retrieved $\mathrm{CO}$ using the AERI water vapor profiles closely follow the temporal variations in AERI PWV. However, CO retrievals using the AERI profiles scaled by the MWR PWV are much smoother but show temporal trends independent of the MWR PWV. Our v2 AERI CO retrieval algorithm scales the AERI retrieved water vapor profiles by the uniform ratio of $\mathrm{PWV}_{\mathrm{MWR}} / \mathrm{PWV}$ AERI determined separately for each AERI spectrum. For the next version of the retrieval algorithm an option to retrieve $\mathrm{CO}$ and $\mathrm{H}_{2} \mathrm{O}$ jointly will be considered.

\subsection{Influence of scattered light}

The version of kCARTA used in this work calculates radiances for aerosol-free and cloud-free atmospheres and it uses empirically-based corrections for water vapor continuum 


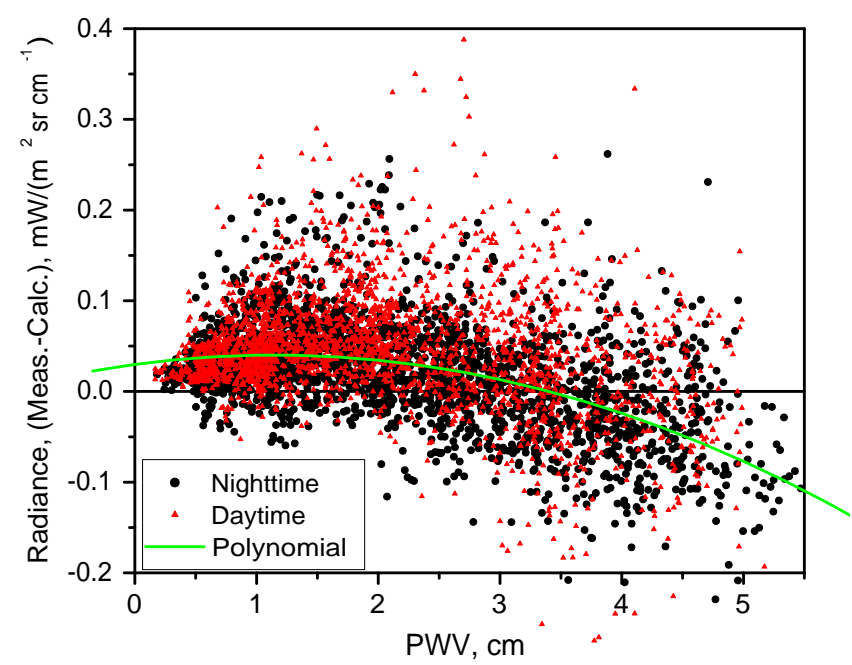

Fig. 5. Radiances averaged over 2 spectral intervals taken together: between $2142.7-2144.1 \mathrm{~cm}^{-1}$ and $2167.2-2168.7 \mathrm{~cm}^{-1}$ used for verification of kCARTA calculations. Differences between measured and calculated radiances for daytime and nighttime are plotted as a function of PWV.

emission/absorption. It does not take into account continuum emission/absorption from any short-lived complexes of molecules, e.g., water dimers. Because clouds and aerosols are not included, there is no accounting for scattered sunlight. To estimate contributions from these ignored factors, observed radiances in two transparent intervals of the spectra, $2142.7-2144.1 \mathrm{~cm}^{-1}$ and $2167.2-2168.7 \mathrm{~cm}^{-1}$ (black bars in Fig. 1), are compared to those calculated by kCARTA. Figure 5 demonstrates that this radiance difference (RD) mostly lies inside the limits $\pm 0.1 \mathrm{~mW} /\left(\mathrm{sr} \mathrm{m}^{2} \mathrm{~cm}^{-1}\right)$ for the entire range of PWV experienced at the SGP. For PWV $<3 \mathrm{~cm}$, $\mathrm{RD}$ is slightly positive on average: $(0.04 \pm 0.04)$ in the same units. At larger PWV, RD diminishes and becomes negative for the largest observed PWV. Overall, the RD is slightly larger during daytime than at night.

We believe the RD pattern evident in Fig. 5 arises from an incomplete accounting for the following sources of radiation: (i) emission from aerosols and thin clouds themselves, (ii) water vapor continuum emission/absorption, and (iii) sunlight scattered from aerosols and clouds. Cases with thick clouds are removed by the previously discussed cloud filter procedure. Emission from aerosols and thin clouds themselves would be expected to exhibit no diurnal variation and should not depend on the total amount of water vapor, i.e., PWV. Although an error in water vapor continuum also should show no diurnal variation, it would display an increasingly significant impact with both PWV and temperature. Scattering of solar photons should correlate strongly with the solar zenith angle and be maximal around noon. The quasiconstant positive RD for $\mathrm{PWV}<3 \mathrm{~cm}$ is consistent with the presence of emission from aerosols and thin clouds in the
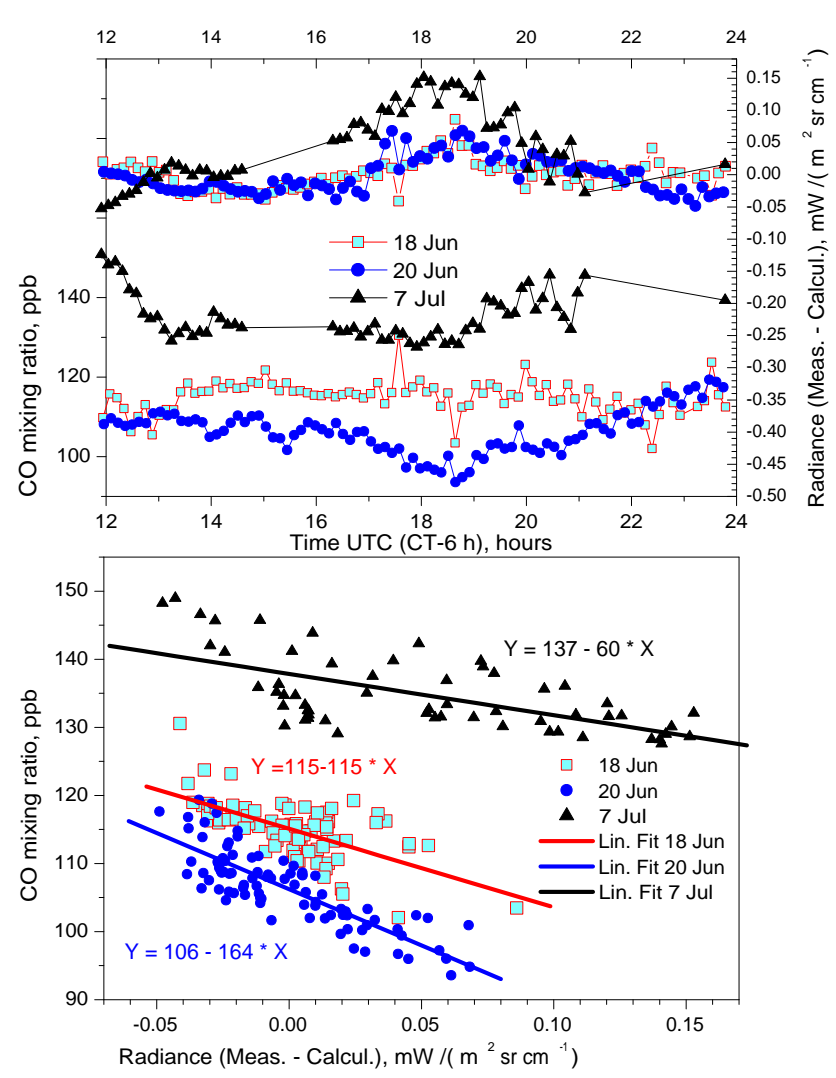

Fig. 6. Top panel: the top three curves (right $y$-axis) illustrate daily variations of the radiance differences (RD) for three days in 2006 in two transparent windows of the CO band (see Fig. 1). The bottom three curves (left $y$-axis) show the corresponding CO mixing ratio retrieved from the AERI spectra for these days. Bottom panel: the $\mathrm{CO}$ and $\mathrm{RD}$ points from the top panel that are plotted against each other for each of the three days along with the best fit linear regression lines.

measured spectra ignored by the forward model. Little diurnal variation is apparent. The lowest RD is close to zero and occurs on the clearest days. For $>3 \mathrm{~cm}$, a decreasing trend appears. This negative trend might be explained by an overestimation of water vapor continuum emission which is more evident as the atmospheric water vapor amount and temperature increase.

The solar radiation scattered by aerosols is expected to have a maximum at local solar noon ( 18:30 UTC). Three examples of cloud-free days in 2006 are given in Fig. 6 (another example is displayed in Fig. 10). Anticorrelation between single measurements of $\mathrm{CO}$ and corresponding radiance errors is obvious (squared correlation coefficients are around -0.7), particularly for 18 and 20 June. Moreover, the time-series of retrieved $\mathrm{CO}$ for these two days exhibits a minimum roughly symmetric about local solar noon, $\sim 18: 30$ UTC. Absent other factors and assuming constant $\mathrm{CO}$, the retrieved $\mathrm{CO}$ would minimize at solar noon due to the filling in of the transparent $\mathrm{CO}$ line wings by 
scattered solar photons. However, the amount of solar scattering also depends on the amount (total optical depth), type, and vertical distribution of aerosols present. This variation is evident in the different slopes of regression lines $S$ (bottom panel) for these three days varying between -60 and $-164 \mathrm{ppb} / \mathrm{mW} /\left(\mathrm{m}^{2} \mathrm{srcm}^{-1}\right)$. This, and even larger, range of regression slopes is representative of the entire SGP AERI $\mathrm{CO}$ retrieval data set. Thus, it is impossible to determine a single value of $S$ that fits most of data.

Figure 7 illustrates our second attempt to derive a correction algorithm for scattered sunlight through examination of the mean diurnal cycle of retrieved CO from all 2006 AERI spectra. Obviously the v1 CO retrievals (bottom curve, blue with pink diamonds) are anticorrelated with the mean $\mathrm{RD}$ (top curve, thin black line). The other curves represent linear subtraction of $S^{*} \mathrm{RD}$ values to the hourly mean v1 CO retrievals. Trial values of $S$ range from 0 (i.e., CO v1) to -190 . As the value of $S$ increases, the anticorrelation evolves into a correlation. The case with $S=-40$ is close to the minimal correlation between $\mathrm{CO}$ and $\mathrm{RD}$. We chose this value of $S$ for correction of scattered sunlight in the v2 AERI $\mathrm{CO}$ retrievals. However, on average, a $7 \mathrm{ppb}$ diurnal cycle of $\mathrm{CO}$ remains even after correction. This diurnal cycle might be real and will be compared with in situ measurements in the discussion section.

\subsection{Summary of errors}

Six major sources of error influence the accuracy of the retrieved CO: (1) spectral noise, (2) errors in the AERI spectral calibration, 3) errors in the temperature profiles, (4) errors in the $\mathrm{H}_{2} \mathrm{O}$ profiles, 5) emission from aerosols and thin clouds, and (6) scattered sunlight. The spectral noise in the CO region $\left(2100-2200 \mathrm{~cm}^{-1}\right)$ is on the order of 0.005 $\mathrm{mW} /\left(\mathrm{m}^{2} \mathrm{srcm}^{-1}\right)$. This spectral noise causes an error of about $0.75 \%$ in the retrieved $\mathrm{CO}$ (He et al., 2001).

The required accuracy of AERI spectral calibration is estimated by Knuteson et al. (2004a) as "better than $0.01 \mathrm{~cm}^{-1}$ ". This accuracy of the spectral calibration was confirmed by Knuteson et al. (2004b) using HITRAN-based calculations of downwelling radiance. Special retrievals for model spectra shifted by $0.01 \mathrm{~cm}^{-1}$ along the wavenumber scale in both directions have been performed by us and the error in $\mathrm{CO}$ amount was found less than $0.1 \%$.

Feltz et al. (1998) investigated the accuracy of AERI temperature and water vapor profile retrievals. The influence of these errors on CO was estimated by He et al. (2001), who obtained $1.5 \%$ (temperature) and $2.5 \%$ (water vapor). Their analysis, however, did not include the most humid days and PWV from integrated AERI $\mathrm{H}_{2} \mathrm{O}$ profiles was not compared to MWR data. We found that for PVW $>3 \mathrm{~cm}$ AERI-derived PVW is overestimated in comparison with the MWR-derived value by $25-30 \%$. This error results in 15$20 \%$ error in CO. However, constraining the water vapor profiles by MWR-derived PVW reduces this uncertainty down

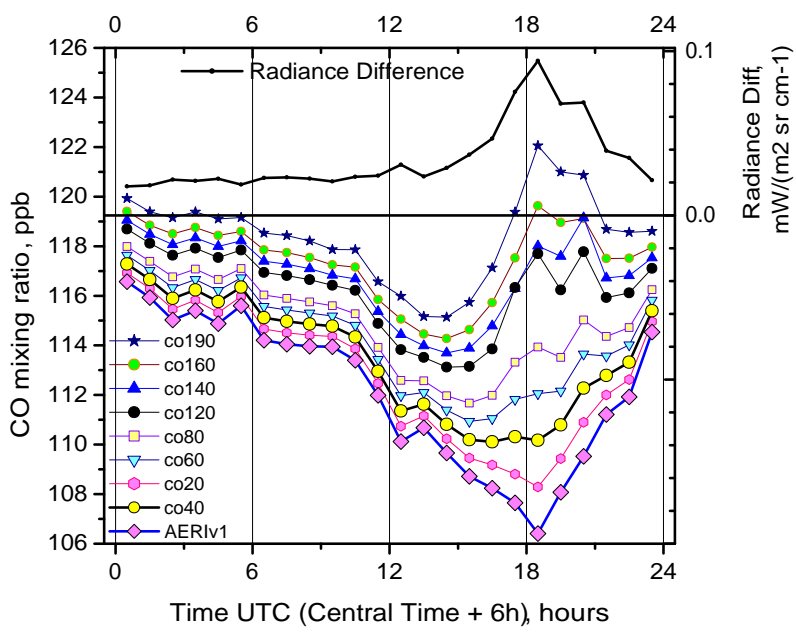

Fig. 7. Mean diurnal cycles. Top curve and right scale: a difference between measured and calculated radiance (RD) in the windowsBottom curves and left scale: mean diurnal cycles of $\mathrm{CO}$ mixing ratio retrieved from the AERI spectra for 2006 and corrected for the scattered light using for different slopes, $S$, of the correlation between CO and RD. The AERI v2 curve corresponds to the slope of -40 where the anticorrelation of $\mathrm{CO}$ and RD minimizes.

to $3 \%$. Temperature profile errors, according to Feltz et al. (1998) do not exceed a few K. These errors propagate in the errors of $\mathrm{CO}$ retrievals as $\pm 1.5 \%$, for most real synoptic situations.

CO's sensitivity to radiance error due to missing nongaseous components in the forward model was investigated during days with stable in situ $\mathrm{CO}$ measured at the tower and changing solar radiance around noon. The retrieved CO changes by $1 \%$ for the RD changing by $0.02 \mathrm{~mW} /\left(\mathrm{m}^{2}\right.$ $\left.\mathrm{srcm}^{-1}\right)$. The error due to aerosol and thin clouds is different for PVW $<3 \mathrm{~cm}$ and for PVW $>3 \mathrm{~cm}$. For low humidity, this RMS error is less than $2 \%$, for high humidity it is around $4 \%$. In this paper we tried to correct for this error and generally v2 is more accurate than v1 for nighttime. Around noon, however, the error may be as high as $10-20 \%$ in cases of strong scattering from aerosols.

The total RMS error of one CO measurement can be estimated, assuming them statistically independent, as $\pm 4 \%$ for low humidity days, and $\pm 6 \%$ for high humidity days. Around noon, a special consideration is necessary and independent estimates of aerosol concentrations are required; otherwise $\mathrm{CO}$ amounts might be underestimated by $15-20 \%$.

\section{Validation}

As previously mentioned, three independent correlative data sets were used to build composite ground-truth $\mathrm{CO}$ profiles at the SGP site for validation of AERI CO retrievals: (i) quasi-continuous in situ $\mathrm{CO}$ measurements from the 60 $\mathrm{m}$ tower at the SGP (Biraud et al., 2007), (ii) in situ CO profiles measured from aircraft between $83 \mathrm{~m}$ and $4000 \mathrm{~m}$ 
above the ground above the SGP (Sweeney et al., 2010; http: //www.esrl.noaa.gov/gmd/ccgg/aircraft/index.html), and (iii) $\mathrm{CO}$ profiles retrieved from AIRS for altitudes above $5 \mathrm{~km}$ (McMillan et al., 2009b). An example composite profile is plotted in Fig. 2.

In situ CO measurements from the $60 \mathrm{~m}$ tower $(413 \mathrm{~m}$ a.s.l. at the foot) at the SGP site are acquired by the Lawrence Berkeley National Laboratory (LBNL) using a non-dispersive infrared gas correlation instrument (Thermo Scientific TE-48C). This instrument has been modified with additional pressure control, frequent zero correction and multi-point calibrations to provide precision and accuracy near 5 ppbv judged by comparison with NOAA network flask measurements (Potosnak et al., 1999).

The in situ CO profiles at the SGP site are measured weekly by the NOAA Earth System Resources Laboratory (ESRL) using an automated programmable flask package operated on a small aircraft. The flasks are filled by air at standard heights above sea level (a.s.1.): 457.2, 609.6, 914.4, 1219.2, 1524.0, 1828.8, 2438.4, 3048.0, 3657.6, $4572.0 \mathrm{~m}$ a.s.l. (the surface altitude at SGP is $374 \mathrm{~m}$ a.s.l.). The flasks are returned to NOAA/ESRL for analysis via gas chromatography to determine $\mathrm{CO}$ mixing ratios (Novelli et al., 1998). Measurements are reported in units of nanomol $/ \mathrm{mol}\left(10^{-9} \mathrm{~mol} \mathrm{CO}\right.$ per mol of dry air, or parts per billion, ppbv, or ppb) relative to the WMO CO scale (Novelli et al., 1991, 1993). Reproducibility of the measurements, based on repeated analysis of air from a high-pressure cylinder, is $1 \mathrm{ppb}$ at $50 \mathrm{ppb}$ and $2 \mathrm{ppb}$ at $200 \mathrm{ppb}$. From 2006-2008 there were 98 days when the time of aircraft sounding $\pm 0.5 \mathrm{~h}$ matched both AERI and in situ data. AIRS CO data, version 5 , level 3 for ascending orbits, i.e. around noon local time, were used to characterize the $\mathrm{CO}$ distribution above $5 \mathrm{~km}$. As illustrated in Fig. 2, AERI sensitivity to these altitudes is small and the $\pm 10 \%$ accuracy of AIRS northern hemispheric CO retrievals (McMillan et al., 2009b) is quite sufficient for our goals. The sensitivity of the $\mathrm{CO}$ abundance retrieved from an AERI spectrum to the $\mathrm{CO}$ amount at different heights is quantified by the averaging kernel (AK) as is common to all inverse techniques (Backus and Gilbert, 1970; Conrath 1972; Rodgers and Connor, 2003). Because of the formulation of the AERI CO retrieval algorithm, AKs must be computed by brute force. That is, layer by layer we perturb the $\mathrm{CO}$ abundance, compute a new spectrum, and perform a $\mathrm{CO}$ retrieval on the perturbed spectrum. The difference between the $\mathrm{CO}$ amount retrieved from the unperturbed spectrum and that retrieved from the perturbed spectrum yields the sensitivity to the perturbed layer. The ensemble of these differences yields the AK. Using the standard 100 pressure layers in kCARTA requires performing $101 \mathrm{CO}$ retrievals (unperturbed +100 perturbations). Thus, AKs were calculated only for each day with a matching validation profile. As illustrated in Fig. 2, the AERI CO AK typically is rather broad with a maximum at or just above the surface.
In practice, AERI CO AKs were calculated using Jacobians computed by the kCARTA forward model. This greatly speeds the computation of the perturbed spectra as described below. For each matching day, the mean temperature and water vapor profiles retrieved from AERI spectra near the time of the aircraft profile were input to kCARTA along with a 100 ppbv constant tropospheric $\mathrm{CO}$ mixing ratio profile to produce a baseline synthetic downwelling infrared spectrum and Jacobians on the standard kCARTA 100 pressure layers. The Jacobian for each layer is defined as

\section{$\frac{\Delta \text { Radiance }}{\Delta \text { CarbonMonoxide }}$}

Therefore, the radiance change due to a perturbation in $\mathrm{CO}$ is simply given by multiplying each level's Jacobian by the magnitude of the $\mathrm{CO}$ change. Because the Jacobians are valid only for small changes in gas amount, we chose a 5\% perturbation factor for each layer. First, the v1 AERI CO retrieval algorithm is run on the unperturbed atmosphere to compute the baseline CO retrieval. Next, the v1 AERI CO retrieval algorithm is run 100 times using each level's radiance change plus the original downwelling infrared spectrum from kCARTA. A larger value of CO retrieved for the perturbation of a given pressure layer indicates the retrieval's increased sensitivity to that layer. The ensemble of retrieved CO differences is defined as the $\mathrm{AK}$ by the following equation:

$\mathrm{AK}_{i}=\frac{\text { RetrievedCO }}{i}-$ BaseCO $_{\text {DeltaCO }}$,

where $i=$ index from 1 to 100 of the standard kCARTA pressure layers,

$\mathrm{AK}_{i}=$ averaging kernel value for layer $i$,

Retrieved $\mathrm{CO}_{i}=\mathrm{CO}$ total column (TC) retrieved from the spectrum computed by perturbing the $\mathrm{CO}$ amount in layer $i$,

Base $C O=\mathrm{CO}$ TC for the unperturbed spectrum,

$\operatorname{DeltaCO}_{i}=$ the change in CO TC in layer $i$.

The resulting averaging kernel is a unit-less number for each of the $100 \mathrm{kCARTA}$ radiative transfer layers corresponding to the sensitivity of the AERI v1 CO retrieval algorithm to a change in gas amount in each layer. Perhaps more important than the graphical visualization of AERI's vertical sensitivity, the averaging kernels are crucial to quantitative validation of the retrieval algorithm. Following Rodgers and Connor (2003), the composite ground-truth CO vertical profiles (True ${ }_{\mathrm{CO}}$ ) were convolved with the a priori $100 \mathrm{ppbv}$ constant tropospheric mixing ratio profile (Apriori $\mathbf{C O}_{\mathrm{CO}}$ ) and the averaging kernel diagonal matrix (AK) for each matching day to convert the composite ground-truth profile to the 


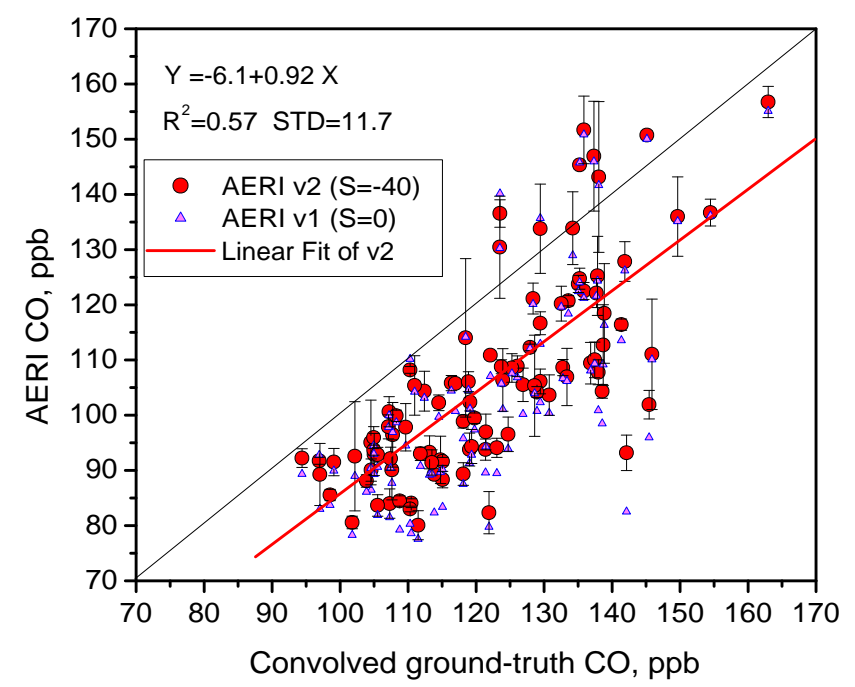

Fig. 8. Comparison of v1 and v2 CO mixing ratios retrieved from the AERI spectra with convolved composite ground-truth profiles (see Fig. 2). Vertical bars are STD variations of AERI retrievals for the 1-hour-long interval corresponding to the aircraft profile. The red line is the linear fit for AERI v2.

AERI CO retrieval algorithm measurement space using the follow matrix equation:

$$
\text { Convolved }_{\mathrm{CO}}=\text { Apriori }_{\mathrm{CO}}+\mathbf{A K}^{*}\left(\text { True }_{\mathrm{CO}}-\text { Apriori }_{\mathrm{CO}}\right) \text {. }
$$

Figure 8 presents the comparison of the AERI v2 retrieved $\mathrm{CO}$ to the vertically averaged Convolved $\mathrm{CO}$ for the 98 matching days. Overall, the AERI v2 retrievals (with a slope of dependence on RD $S=-40$, as chosen above) are biased low by $\sim 16 \mathrm{ppbv}$ with a standard deviation (STD) of individual data points of $\pm 11.7 \mathrm{ppbv}$, and a squared correlation coefficient $R^{2}=0.57$. For comparison, the original AERI v1 CO retrievals are shown and exhibit a larger negative bias. A stronger dependence of $\mathrm{CO}$ on RD (not shown) with a slope $S=-160$ improves the bias ( $-9.2 \mathrm{ppbv})$, STD $( \pm 9.6 \mathrm{ppbv})$, and $R^{2}(0.65)$, and $\mathrm{STD}= \pm 9.6 \mathrm{ppbv}$. However, as discussed with Fig. 7, $S=-160$ distorts the mean diurnal cycle. Thus, we have chosen $S=-40$ for the v2 scattered sunlight correction. Data users are advised to refer to RD as a flag for $\mathrm{CO}$ retrieval accuracy; for $\mathrm{RD}>0.05$, an additional negative error in retrieved $\mathrm{CO}$ around noon of up to $10-20 \mathrm{ppb}$ is possible.

The demonstrated comparison of $\mathrm{CO}$ mixing ratio measured using different independent techniques raises a question on the nature of the significant bias. Aircraft soundings were carried out during daytime when the above mentioned aerosol scattering distorts the results of AERI CO retrievals. So, taking aerosols into account is expected to improve the agreement.

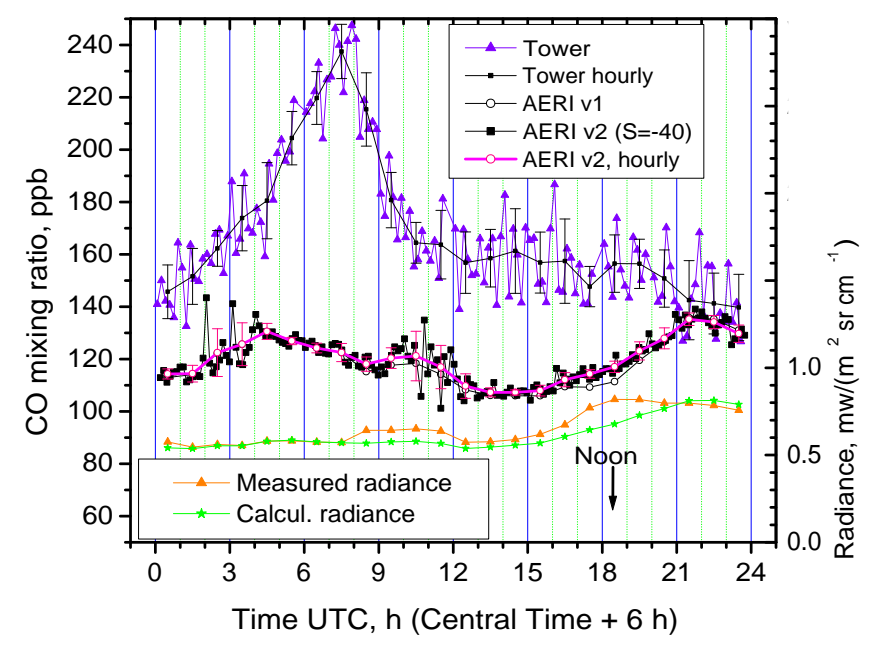

Fig. 9. Example measurement results for clear sky conditions of 19 May 2006. The differences between the two versions of the AERI retrievals are proportional to the radiance differences (bottom two curves) and amount to $\sim 5 \mathrm{ppbv}$ around noon for this specific day.

\section{Results and discussion}

\subsection{Diurnal cycle}

Figure 9 illustrates a typical example of $\mathrm{CO}$ behavior inside the BL (in situ, $60 \mathrm{~m}$ tower) and $\mathrm{CO}$ mixing ratio supplied by AERI retrievals. The small scatter for both data sets practically disappears after hourly averaging. On this day, the differences between $\mathrm{v} 1$ and $\mathrm{v} 2$ of the AERI CO retrieval are small with a maximum near noon of $\sim 5$ ppbv. The diurnal cycles of BL CO and that retrieved from AERI are significantly different. The large increase in tower $\mathrm{CO}$ overnight could be due to trapping of surface $\mathrm{CO}$ emissions in a thin nocturnal boundary layer. AERI's sensitivity to a greater depth of the atmosphere would mute this impact resulting in the apparent differences. Close to dawn, this stable layer is mixed and the tower values decline as CO is vertically redistributed. This redistribution has little impact on the AERI retrievals due to its significant vertical averaging.

Figure 10 gives an example of a clear summer day with a maximum effect of scattered sunlight on the $\mathrm{CO}$ retrievals. The tower measurements indicate no accumulation of $\mathrm{CO}$ in the BL during the night. The empirical slope of $\mathrm{CO}$ versus RD around noon amounts to -192 and the AERI v2 underestimation may be as large as $12 \mathrm{ppb}$ at noon. For other days not shown here, long-range transport of $\mathrm{CO}$ above the boundary layer can appear as increases in the AERI retrieved CO while the tower sees only the local in situ conditions. Further analysis of such cases is beyond the scope of this study and will be pursued in future publications. 


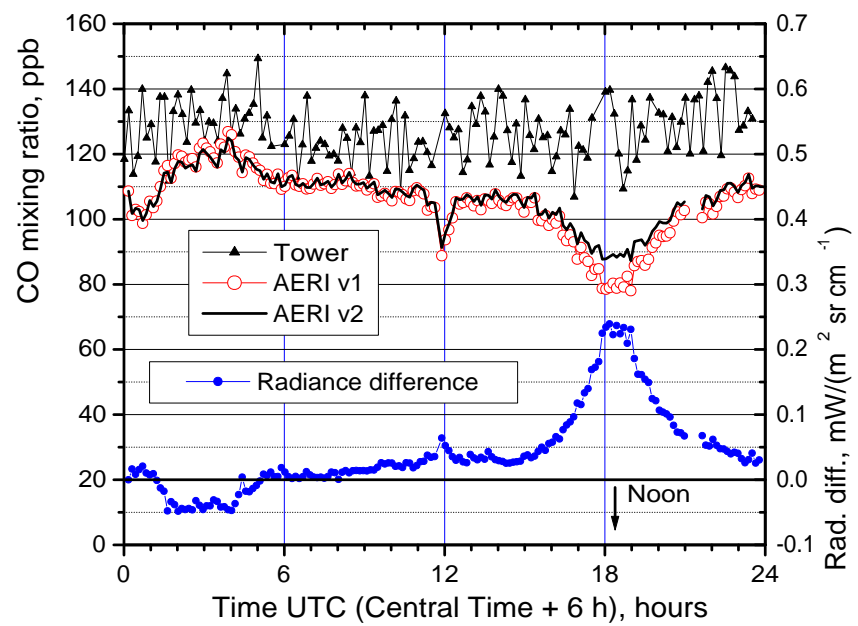

Fig. 10. Example measurement results for clear sky conditions of 8 June 2007. A difference between measured and calculated radiances RD (blue dots) anticorrelates with the AERI CO v1 around local noon (slope $=-198, R^{2}=0.92$ ). Although the amplitude around noon for AERI CO v2 is less, it appears the correction for scattered sunlight is not complete.

As shown in Fig. 11, the average 2006 diurnal cycle exhibits very similar features to those presented for the one individual day in Fig. 9, although the STDs for both in situ and AERI CO are rather large. The amplitude of the mean diurnal cycle is $\sim 15.7 \mathrm{ppbv}$ for the in situ tower data and $\sim 7.2 \mathrm{ppbv}$ for the AERI v2 CO retrievals. On average, BL CO increases during the night for $\sim 10 \mathrm{~h}$ before relaxing back during the other $\sim 14 \mathrm{~h}$. Not only is the AERI amplitude smaller, the increase appears to be shorter (increasing for $\sim 8 \mathrm{~h}$ and relaxing longer $\sim 16 \mathrm{~h}$ ) and out of phase with the BL CO diurnal cycle. Most likely, some of this phase difference results from the incomplete removal of the scattered sunlight artifact in the AERI v2 CO retrievals around noon.

\subsection{Seasonal cycles and interannual variations}

Throughout 2006, 2007, and 2008, both the tower in situ and AERI remote sensing instruments operated simultaneously at the SGP site. Figure 12 compares the three seasonal cycles for these years. The general shapes of the $\mathrm{CO}$ seasonal cycles for both sensors agree with the usually observed CO cycle first measured by Dianov-Klokov and Yurganov (1981): maximum in spring and minimum in late summer or early autumn. Until July 2008, both AERI and tower CO monthly mean data did not differ from year to year, with exception of June-July 2006. However, in November and December, 2008, both sensors recorded CO mixing ratios 10-20 ppbv lower than during the two previous years. The influence of smaller $\mathrm{CO}$ emissions from fossil fuel burning in the USA during the economic recession is the most likely explanation of this effect. Below, we compare the SGP observations to the global and regional satellite data.

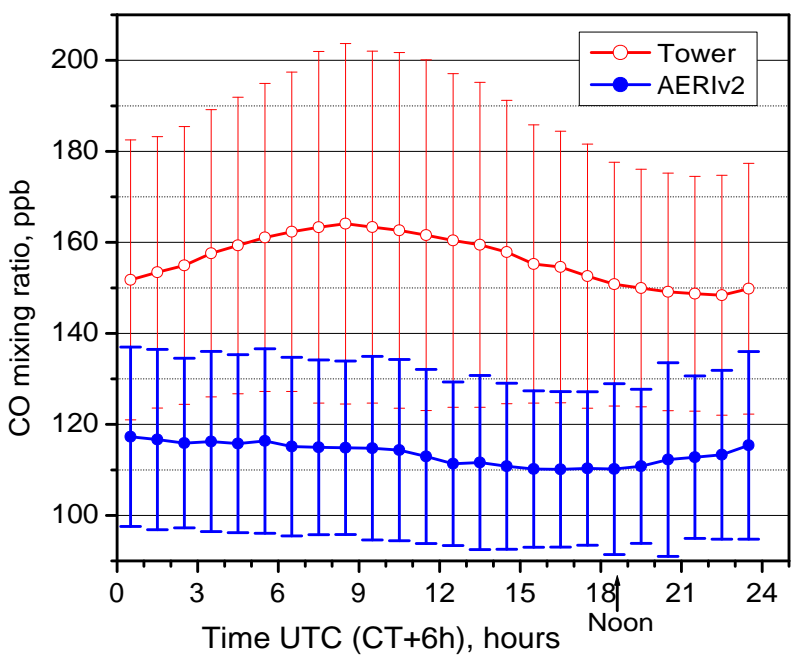

Fig. 11. Average 2006 diurnal cycles for in situ measurements at the 60-m-tall tower and CO retrieved from the AERI v2. Vertical bars are the standard deviations of hourly means.

Figure 13 presents the anomaly of $\mathrm{CO}$ for 2002-2009. The seasonal cycle averaged over January 2004-December 2007 was subtracted from the monthly mean $\mathrm{CO}$ data. Calculation of the anomaly is equivalent to deseasonalizing the data. Then, anomalies of monthly means were divided by the mean 2004-2007 seasonal cycle and plotted in percent. Similar anomalies of the CO total column measured by AIRS are given for comparison. AIRS CO total columns were averaged for the NH mid-latitudes, for North America, and for the tropics. The most substantial positive anomalies were observed in 2002 and 2003. As Yurganov et al. (2005) found, Siberian fires during that time affected the entire northern hemisphere: total column CO increased by $20 \%$, and surface mixing ratios increased by $35 \%$ (in comparison with 2000 2001). The $25 \%$ increase observed by the AERI at SGP lies between those two estimates. The differences between total column and surface measurements reflect the intermediate coverage of the AERI CO retrieval averaging the lowest $2 \mathrm{~km}$ of the atmosphere.

The largest negative anomaly was observed by the two sensors around January 2009 (a similar effect was observed by MOPITT, according to Yurganov et al., 2010). Is the decrease of CO over the SGP, North America, and the entire NH a result of $\mathrm{CO}$ emission diminution from fossil fuel burning triggered by the economic recession? A more comprehensive study including all available data and global chemical transport modeling is necessary. However, at this point, the coincident timing of the minimum for SGP, North America and the NH in January 2009 could be evidence for this. During November, December, and January wildfire activity inside the $\mathrm{NH}$ mid-latitudes is almost lacking and its influence on $\mathrm{CO}$ burden is minimal. Furthermore, an examination of the Global Fire Emission Data (GFED2) inventory by Yurganov et al. (2010) found little change in this minimal fire activity 


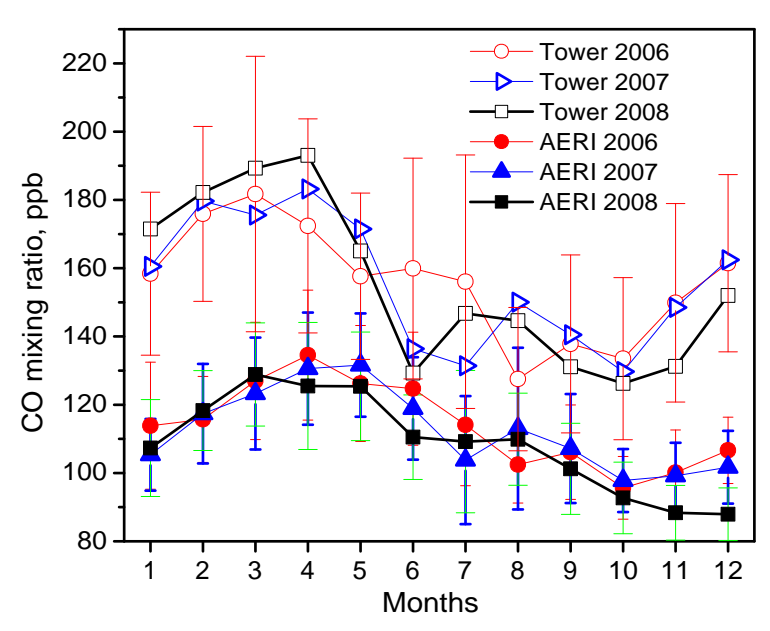

Fig. 12. Mean seasonal cycles for 3 years of simultaneous in situ and remote sensing CO observations at the SGP. Error bars are standard deviations of daily means. For clarity, error bars for the in situ data are only given for 2006.

in the NH in late 2008 and early 2009. In contrast, Yurganov et al. (2010) reported lower than usual CO burdens measured by MOPITT and AIRS in the tropics as shown in Fig. 13. GFED2 also indicated a lower than usual amount of fire activity in Brazil and Indonesia in the second half of 2008 (Yurganov et al., 2010).

Concluding this section, the influence of tropical CO emissions on the $\mathrm{NH}$ mid-latitudes must be quantified, and the timing of transport from the tropics to the $\mathrm{NH}$ mid-latitudes must be determined. The three-month temporal lag of $\mathrm{CO}$ burden minima between the tropics and NH mid-latitudes could result from transport of lower $\mathrm{CO}$ burdens from south to north. The smaller percent decrease in the tropics than in the NH should not be misleading: the tropics contain about half of the global air mass and the absolute values of the $\mathrm{CO}$ burden anomaly are higher there than in the NH. Most likely, however, the NH CO burden in 2008-2009 decreased due to a combination of changes in the $\mathrm{CO}$ emissions inside the $\mathrm{NH}$ and reduced transport from the tropics.

\section{Conclusions}

Spectra of downwelling IR radiance acquired by AERIs in the ARM network, including SGP, contain very useful information about trace gases. Other than water vapor, $\mathrm{CO}$ is the most easily retrievable trace gas from these spectra. This paper describes an improved algorithm for $\mathrm{CO}$ retrieval. It is based on AERI measurements of the downwelling IR radiance in the $\mathrm{CO}$ fundamental band. Temperature and water vapor profiles retrieved from the same spectra are important input parameters for this algorithm, but they must be augmented by additional measurements of the total amount of water in the atmosphere. Retrievals of PWV from the MWR instrument at SGP were used to scale the less accurate AERI

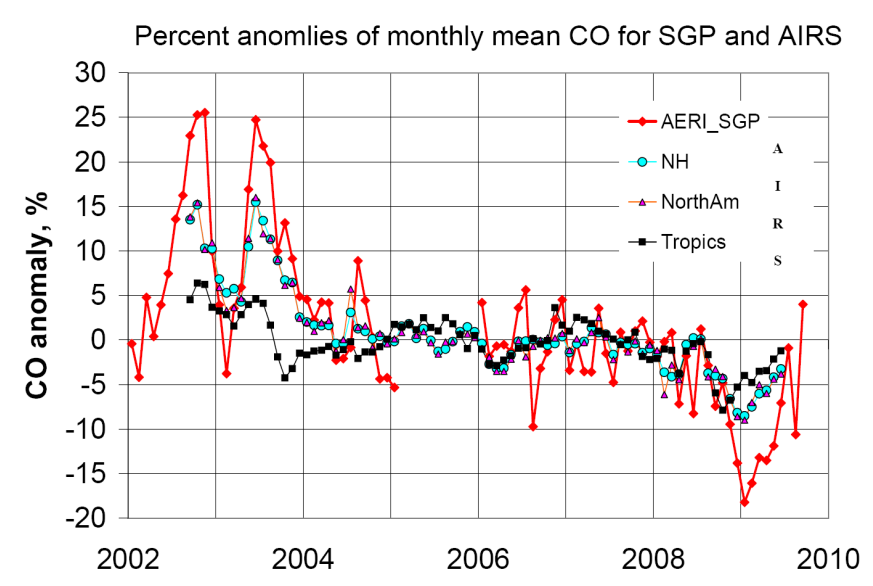

Fig. 13. Anomalies of monthly mean $\mathrm{CO}$ retrieved by the AERI v2 referenced to the seasonal cycle calculated from the period from January 2004 through December 2007. Plotted for comparison are AIRS-derived total column $\mathrm{CO}$ anomalies for the $\mathrm{NH}$ (between $30^{\circ} \mathrm{N}$ and $70^{\circ} \mathrm{N}$ ), North America (bounded by $30^{\circ} \mathrm{N}, 70^{\circ} \mathrm{N}$; $\left.60^{\circ} \mathrm{W}, 170^{\circ} \mathrm{W}\right)$, and the tropical belt $\left(30^{\circ} \mathrm{S}-30^{\circ} \mathrm{N}\right)$ corrected according to Yurganov et al. (2010).

water vapor retrievals. In addition, the version of kCARTA employed as a forward model neglects scattering of sunlight by aerosols and clouds. This study proposes an empirical correction to account for the additional scattered radiation using measured radiances in the most transparent portions of the CO band. The radiance difference (RD) between this measured radiance and that calculated by the forward model usually is small. In some cases, however, incoming solar radiance scattered by aerosols or clouds is significant, and RD is higher than usual. Unfortunately, we failed to determine any uniform dependence between $\mathrm{CO}$ errors and RD. The AERI v2 CO algorithm includes just a simple linear relationship between them and an additional underestimation at noon may be as high as 10-20 ppb.

Validation of the AERI v2 CO retrieval algorithm was performed using independent simultaneous $\mathrm{CO}$ in situ sampling from a 60 -m-tall tower and aircraft sampling up to $4 \mathrm{~km}$ above the surface. Above $5 \mathrm{~km}$, AIRS v5 retrievals were used to complete the composite ground-truth profiles. The squared correlation coefficient between ground-truth $\mathrm{CO}$ profiles convolved with the AERI averaging kernels (AK) and AERI CO retrievals is 0.57 with a slope of 0.92 . However, a negative 16-ppb bias remains. At this point, we interpret this bias as an indication that the AERI retrievals are more sensitive to lower $\mathrm{CO}$ concentrations in the mean free troposphere accounted for by the computed AK. A new AERI CO retrieval algorithm is in development to separately retrieve $\mathrm{BL}$ and free tropospheric $\mathrm{CO}$ concentrations.

A comparison of simultaneously measured in situ $\mathrm{CO}$ in the BL and remotely in the lower $2 \mathrm{~km}$ supplies very useful information about changes in $\mathrm{CO}$ vertical distribution with high temporal resolution. For instance, during nighttime, 
the $\mathrm{CO}$ mixing ratio in the $\mathrm{BL}$ usually increases during the development of a thin, stable nocturnal BL. Conversely, $\mathrm{CO}$ measured by the AERI does not show this effect. Near dawn, the nocturnal $\mathrm{BL}$ is destroyed and $\mathrm{CO}$ is redistributed vertically. This causes a significant $\mathrm{CO}$ decrease near the surface, but the vertically averaged AERI CO retrievals do not change.

Comparison of the seasonal cycle of $\mathrm{CO}$ in the $\mathrm{BL}$ and that measured by the AERI also is illustrative. The seasonal spring maximum of the BL CO is significantly larger than that measured by the AERI due to pollution accumulated by the end of winter time. However, throughout May both curves converge and in June the atmosphere becomes almost well mixed. The same effect was first observed in springsummer of 1995 in Alaska in the course of a similar experiment (Yurganov et al., 1998). Through the summer time the relation between these two data sets depends on the intensity of surface emissions, the rate of vertical mixing, and advection of $\mathrm{CO}$ from remote sources such as forest fires.

Deseasonalized monthly AERI CO retrievals are in agreement with satellite, surface, and total column measurements throughout the 2000s. The greatest influence on these variations was due to Siberian forest fires in 2002 and 2003, up to a $25 \%$ increase. Interestingly, this value lies between the $15 \%$ increase determined from total columns measured by AIRS (20\% increase measured by MOPITT (Yurganov et al., $2005 ; 2010)$ and the $35 \%$ increase determined from NH midlatitude surface measurements (Yurganov et al., 2005). This confirms the intermediate altitude coverage of a sky-viewing instrument like the AERI in comparison to ground-based in situ measurements and total columns measured from ground and space. Therefore, AERI measurements complement existing monitoring facilities and do not duplicate them.

Finally, after August 2008, deseasonalized CO mixing ratios measured by the AERI decreased to a minimum in January 2009 before recovering. The same behavior of the $\mathrm{CO}$ burden for North America and the entire NH mid-latitudes was observed from space by MOPITT and AIRS. The most likely explanation for this effect is a diminution of the $\mathrm{NH}$ $\mathrm{CO}$ emission from fossil fuels connected with the global economic recession. Some effect of diminished biomass burning in the tropics is possible, but a quantitative estimate of this effect requires detailed modeling of global transport.

Acknowledgements. This research was supported through a subcontract with the AIRS Project Office at JPL; by NASA grants NAG5-11653, NNG04GN42G, and NNG06GB06G, by NSF grant OISE-0827507_00004084, and by NOAA grant NA04AOAR4310095. The in situ measurements at the tower and the aircraft sampling were supported by the Director, Office of Science, Office of Biological and Environmental Research, Climate Change Research Division, of the US Department of Energy under Contract No. DE-AC02-05CH11231. The authors are grateful to Paul Novelli for great efforts to keep the high quality of CO flask analysis. We thank Bruce Doddridge for his support of initial AERI $\mathrm{CO}$ validation during CAMEX-2.
Edited by: K. Strong

\section{References}

ACRF Annual Report: DOE/SC-ARM-0805, http://www.arm.gov/ publications/programdocs/doe-sc-arm-0805.pdf, 2008.

Backus G. E. and Gilbert J. F.: Uniqueness in the inversion of gross earth data, Phil. Trans. R. Soc., 266, 123-192, 1970.

Bergamaschi, P., Hein, R., Heimann, M., and Crutzen, P. J.: Inverse modeling of the global $\mathrm{CO}$ cycle, 1 , Inversion of $\mathrm{CO}$ mixing ratios , J. Geophys. Res., 105(D2), 1909 (1999JD900818), 2000.

Biraud, S. C., Torn, M., Riley, W. J., et al.: Regional Carbon Fluxes and Atmospheric Carbon Dynamics in the Southern Great Plains during the 2007 CLASIC intensive, Eos Trans. AGU, 88(52), Fall Meet. Suppl., Abstract B43D-1595, 2007.

Buchwitz, M., de Beek, R., Bramstedt, K., Nol, S., Bovensmann, H., and Burrows, J. P.: Global carbon monoxide as retrieved from SCIAMACHY by WFM-DOAS, Atmos. Chem. Phys., 4, 19451960, doi:10.5194/acp-4-1945-2004, 2004.

Candy, J.: Signal processing, the modern approach, McGraw-Hill, New-York, 1988.

Clerbaux, C., Edwards, D. P., Deeter, M., Emmons, L., Lamarque, J.-F., Tie, X. X., Massie, S. T., and Gille, J.: Carbon monoxide pollution from cities and urban areas observed by the Terra/MOPITT mission, Geophys. Res. Lett., 35, L03817, doi:10.1029/2007GL032300, 2008.

Collard, A. D., Ackerman, S. A., Smith, W. L., Ma, H. E., Revercomb, H. E., Knuteson, R. O., and Lee C.,: Cirrus cloud properties derived from High Spectral Resolution Infrared Spectrometry using FIRE II, Part III: Ground-based HIS results, J. Atmos. Sci., 52(23), 4264-4275, 1995.

Conrath, B. J.: Vertical resolution of temperature profiles obtained from remote sensing measurements, J. Atmos. Sci., 29, 12621271, 1972.

DeSlover, D. H., Smith, W. L., Piironen, P. K., and Eloranta, E. W.: A methodology for measuring cirrus cloud visible-to-infrared spectral optical depth ratios, J. Atmos. Ocean. Tech., 16(2), 251262, 1999.

DeSouza-Machado, S., Strow, L., and Hannon, S.: kCompressed atmospheric radiative transfer algorithm (kCARTA), in Satellite Remote Sensing of Clouds and the Atmosphere, Procs. Of the European Symposium on Aerospace Remote Sensing \#3220, Europto Series, Institute of Electrical Engineers, London, Great Britain, 1997.

Dianov-Klokov, V. I. and Yurganov, L. N.: A spectroscopic study of the global space-time distribution of atmospheric CO, Tellus, v.33, 262-273, 1981.

Edwards, D. P., Emmons, L. K., Gille, J. C., Chu, A., Atti'e, J.-L., Giglio, L., Wood, S. W., Haywood, J., Deeter, M. N., Massie, S. T., Ziskin, D. C., and Drummond J. R.: Satellite-observed pollution from Southern Hemisphere biomass burning, J. Geophys. Res., 111, D14312, doi:10.1029/2005JD006655, 2006.

Fante, R. L.: Signal analysis and estimation: an introduction, John Wiley, Ney-York, 1988.

Feltz, W. F., Smith, W. L., Knuteson, R. O., Revercomb, H. E., Woolf, H. M., and Howell,: H. B.: Meteorological applications of temperature and water vapor retrievals from the ground-based Atmospheric Emitted Radiance Interferometer (AERI), J. Appl. Meteor., 37(9), 857-875, 1998. 
Feltz, W. F., Howell, H. B., Knuteson, R. O., Woolf, H. M., and Revercomb, H. E.: Near continuous profiling of temperature, moisture, and atmospheric stability using the atmospheric emitted radiancen interferometer (AERI), J. Appl. Meteor., 42, 584598, 2003.

Fisher, J. A., Jacob, D. J, Purdy, M. T., et al.: Source attribution and interannual variability of Arctic pollution in spring constrained by aircraft (ARCTAS, ARCPAC) and satellite (AIRS) observations of carbon monoxide, Atmos. Chem. Phys., 10, 977-996, doi:10.5194/acp-10-977-2010, 2010.

Goode, J., Yokelson, R., Susott, R., and Ward, D.: Trace gas emissions from laboratory biomass fires measured by open-path Fourier transform infrared spectroscopy: Fires in grass and surface fuels, J. Geophys. Res., 104(D17), 21237-21245, 1999.

He, H., McMillan, W. W., Knuteson, R. O., Feltz, W. F.: Tropospheric carbon monoxide column density retrieval during Prelaunch MOPITT Validation exercise, Atmos. Environ., 35(3), 509-514, ISSN 1352-2310, doi:10.1016/S1352-2310(00)003344, 2001.

Knuteson, R. O, Revercomb, H. E, Best, F. A., Ciganovich, N. C, Dedecker, R. G., Dirkx, T. P., Ellington, S. C., Feltz, W. F., Garcia, R. K, and Howell, H. B.: Atmospheric Emitted Radiance Interferometer, Part I: Instrument Design, J. Atmos. Oceanic Technol., 21(12), 1763-1776, 2004a.

Knuteson, R.O., Revercomb, H. E, Best, F. A., Ciganovich, N. C., Dedecker, R. G., Dirkx, T. P., Ellington, S. C., Feltz, W. F., Garcia, R. K, Howell, H. B., Smith, W. L., Short, J. F., and Tobin D. C.: Atmospheric Emitted Radiance Interferometer, Part II: Instrument Performance, J. Atmos. Oceanic Technol., 21(12), 1777-1789, 2004b.

Kopacz, M., Jacob, D. J., Fisher, J. A., Logan, J. A., Zhang, L., Megretskaia, I. A., Yantosca, R. M., Singh, K., Henze, D. K., Burrows, J. P., Buchwitz, M., Khlystova, I., McMillan, W. W., Gille, J. C., Edwards, D. P., Eldering, A., Thouret, V., and Nedelec, P.: Global estimates of CO sources with high resolution by adjoint inversion of multiple satellite datasets (MOPITT, AIRS, SCIAMACHY, TES), Atmos. Chem. Phys., 10, 855-876, doi:10.5194/acp-10-855-2010, 2010.

Liljegren, J.C.: Two-channel microwave radiometer for observations of total column precipitable water vapor and cloud liquid water path. Fifth Symposium on Global Change Studies, 262269, 23-28 January 1994, American Meteorological Society, Nashville, Tennessee, 1994.

McMillan, W. W., Strow, L. L., Smith, W. L., Revercomb, H. E., and Huang, H. L.: The detection of enhanced carbon monoxide abundances in remotely sensed infrared spectra of a forest fire smoke plume, Geoph. Res. Lett., 23(22), 3199-3202, 1996.

McMillan, W. W., Strow, L. L., Smith, W. L., Revercomb, H. E., Huang, H. L., Ryan, W. F., Thompson, A. M., and McNamara, D. P.: Remote sensing of CO over the continental US on September 12-13, 1993, J. Geophys. Res., 102(D9), 10,695-10,709, 1997.

McMillan, W. W., He, H., Doddridge, B. G., Feltz, W. F., Knuteson, R. O., McKernan, E., Pougatchev, N. S., Smith, W. L., Strow, L. L., Wang, J., and Yurganov, L.: Validation of carbon monoxide retrievals from up-looking FTIR atmospheric thermal emission spectra, in: Optical Remote Sensing of the Atmosphere, Optical Society of America Technical Digest, 27, 163-165, 1999.

McMillan, W. W., McCourt, M., Revercomb, H., Knuteson, R. O., Christian, T. J., Doddridge, B. G., Hobbs, P. V., Lukovich,
J. V., Novelli, P. C., Piketh, S. J., Sparling, L., Stein, D., Swap, R. J., and Yokelson, R. J.: Tropospheric carbon monoxide measurements from the Scanning High-resolution Interferometer Sounder on 7 September 2000, in southern Africa during SAFARI, J. Geophys. Res., 108, 8492, doi:10.1029/2002JD002335, 2003.

McMillan, W. W., Barnet, C., Strow, L., Chahine, M. T., McCourt, M. L., Warner, J. X., Novelli, P. C., Korontzi, S., Maddy, E. S., and Datta, S.: Daily global maps of carbon monoxide from NASA's Atmospheric Infrared Sounder, Geophys. Res. Lett., 32, L11801, doi:10.1029/2004GL021821, 2005.

McMillan, W. W. and Yurganov, L.: Local, regional, and global views of tropospheric carbon monoxide from the Atmospheric Infrared Sounder (AIRS), Proceedings of SPIE, 6966, Algorithms and Technologies for Multispectral, Hyperspectral, and Ultraspectral Imagery XIV, edited by: Shen, S. S. and Lewis, P. E., 696615, doi:10.1117/12.776983, (11 April 2008), 2008a.

McMillan, W. W., Warner, J. X., McCourt Comer, M., Maddy, E., Chu, A., Sparling, L., Eloranta,E., Hoff, R., Sachse, G., Barnet, C., Razenkov, I., and Wolf, W.: AIRS views transport from 12 to 22 July 2004 Alaskan/Canadian fires: Correlation of AIRS CO and MODIS AOD with forward trajectories and comparison of AIRS CO retrievals with DC-8 in situ measurements during INTEX-A/ICARTT, J. Geophys. Res., 113(D20301), doi:10.102009/2007JD009711, 10, 2008b.

McMillan, W. W., Pierce, R., Sparling, L. C., Osterman, G., McCann, K., Fischer, M. L., Rappenglueck, B., Newton, R., Turner, D. D., Kittaka, C., Evans, K., Biraud, S., Lefer, B., Andrews, A., and Oltmans, S.: An Observational and modeling strategy to investigate the impact of remote sources on local air quality: A Houston, Texas case study from TEXAQS II, J. Geophys. Res., 115, D01301, doi:10.1029/2009JD011973, 2009a.

McMillan, W. W., Evans, K. Barnet, C., Maddy, E., Sachse, G., and Diskin, G.: Validating the AIRS Version 5 CO Retrieval with DACOM in situ Measurements During INTEX-A and -B, IEEE Trans. Geosci. Remote Sens., in review, 2009b.

Minnett, P. J., Knuteson, R. O., Best, F. A., Osborne, B. J., Hanafin, J. A., and Brown, O. B.: The Marine-Atmospheric Emitted Radiance Interferometer: A High-Accuracy, Seagoing Infrared Spectroradiometer, J. Atmos. Oceanic Technol., 18, 994-1013, 2001.

Nalli, N. R, Minnett, P. J., and van Delst, P.: Emissivity and reflection model for calculating unpolarized isotropic water surfaceleaving radiance in the infrared. I: Theoretical development and calculations, Appl. Optics, 47(21), 3701-3721, 2008.

Nedelec, P., Cammas, J.-P., Thouret, V., Athier, G., Cousin, J.-M., Legrand, C., Abonnel, C., Lecoeur, F., Cayez, G., and Marizy, C.: An improved infrared carbon monoxide analyser for routine measurements aboard commercial Airbus aircraft: technical validation and first scientific results of the MOZAIC III programme, Atmos. Chem. Phys., 3, 1551-1564, doi:10.5194/acp-3-15512003, 2003.

Novelli, P. C., Elkins, J. W., and Steele, L. P.: The development and evaluation of a gravimetric reference scale for measurements of atmospheric carbon monoxide, J. Geophys. Res., 96, 1310913121. 1991.

Novelli, P. C., Connors, V. S., Reichle Jr., H. G., et al.: An internally consistent set of globally distributed atmospheric carbon monoxide mixing ratios developed using results from an intercomparison of measurements, J. Geophys. Res., 103(D15), 
19285-19293, 1998.

Novelli, P. C., Masarie, K. A., Lang, P. M., Hall, B. D., Myers, R. C., and Elkins, J. W.: Reanalysis of tropospheric CO trends: Effects of the 1997-1998 wildfires, J. Geophys. Res., 108(D15), 4464, doi:10.1029/2002JD003031, 2003.

Potosnak, M. J., Wofsy, S. C., Denning, A. S., Conway, T. J., Munger, J. W., and Barnes, D. H.: Influence of biotic exchange and combustion sources on atmospheric $\mathrm{CO}_{2}$ concentrations in New England from observations at a forest flux tower, J. Geophys. Res., 104, 9561-9569. 1999.

Reichle, H., Connors, V., Holland, J., Sherrill, R., Wallio, H., Casas, J., Condon, E., Gormsen, B., and Seiler, W.The distribution of middle tropospheric CO during early October 1984, J. Geophys. Res., 95, 9845-9856, 1990.

Rinsland, C. P., Jones., N. B., Connor, B. J., Logan, J. A., Pougatchev, N. S., Goldman, A., Murcray, F. J., Stephen,T. M., Pine, A. S., Zander, R., Mahieu, E., and Demoulin, P.: Northern and southern hemisphere ground-based infrared spectroscopic measurements of tropospheric carbon monoxide and ethane, J. Geophys. Res., 103(D21), 28197-28218, doi:10.1029/98JD02515, 1998.

Rinsland, C. P., Paton-Walsh, C., Jones, N. B., Griffith, D. W. T., Goldman, A., Wood, S. W., Chiou, L., and Meier, A.: High spectral resolution solar absorption measurements of ethylene $\left(\mathrm{C}_{2} \mathrm{H}_{4}\right)$ in a forest fire smoke plume using HITRAN parameters: Tropospheric vertical profile retrieval, J. Quant. Spectrosc. Rad. Transfer, 96, 301-309, 2005.

Rodgers, C. D. and Connor, B. J.: Intercomparison of remote sounding instruments, J. Geophys. Res., 108(D3), 4116, doi:10.1029/2002JD002299, 2003.

Rothman, L. S., Jacquemart, D., Barbe, A., et al.: The HITRAN 2004 molecular spectroscopic database, J. Quant. Spectrosc. Rad. Transfer, 96, 139-204, 2005.

Smith, W. L., Feltz, W. F., Knuteson, R. O., Revercomb, H. B., Howell, H. B., and Woolf, H. M.: The retrieval of planetary boundary layer structure using ground-based infrared spectral radiance measurements, J. Atmos. Oceanic Technol., 16, 323-333, 1999.

Sachse, G. W., Hill, G. F., Wade, L. O., and Perry, M. G.: Fastresponse, high-precision carbon monoxide sensor using a tunable diode laser absorption technique, J. Geophys. Res., 92, 20712081, 1987.

Spivakovsky, C. M., Logan, J. A., Montzka, S. A., et al.: Threedimensional climatological distribution of tropospheric $\mathrm{OH}$ : Update and evaluation, J. Geophys. Res., 105, 8931-8980, 2000.

Sussmann, R. and Borsdorff, T.: Technical Note: Interference errors in infrared remote sounding of the atmosphere, Atmos. Chem. Phys., 7, 3537-3557, doi:10.5194/acp-7-3537-2007, 2007.

Sweeney, C., Karion, A., Wolter, S., Neff, D., Higgs, J. A., Heller, M., Guenther, D., Miller, B. R., Montzka, S. A., Miller, B., Conway, T. J., Dlugokencky, E., Novelli, P. C., Masarie, K., Oltman, S., and Tans, P.: Observations from the NOAA/ESRL Aircraft of Greenhouse Gas Network, Atmos. Chem. Phys., in preparation, 2010.

Turner, D. D., Feltz, W. F., and Ferrare, R. A.: Continuous water vapor profiles from operational ground-based active and passive remote sensors, B. Amer. Meteorol. Soc., 81, 1301-1317, 2000.
Turner, D. D., Tobin, D. C., Clough, S. A., Brown, P. D., Ellingson, R. G., Mlawer, E. J., Knuteson, R. O., Revercomb, H. E., Shippert, T. R., Smith, W. L., and Shephard, M. W.: The QME AERI LBLRTM: A Closure Experiment for Downwelling High Spectral Resolution Infrared Radiance, J. Atmos. Sci., 61, $2657-$ 2675, 2004.

Turner, D. D., Clough, S. A., Liljegren, J. C., Clothiaux, E. E., Cady-Pereira, K., and Gaustad, K. L.: Retrieving precipitable water vapor and liquid water path from Atmospheric Radiation Measurement (ARM) program's microwave radiometers, IEEE Trans. Geosci. Remote Sens., 45(11), 233-252, 2007.

Turquety, S., Hurtmans, D., Hadji-Lazaro, J., Coheur, P.-F., Clerbaux, C., Josset, D., and Tsamalis, C.: Tracking the emission and transport of pollution from wildfires using the IASI CO retrievals: analysis of the summer 2007 Greek fires, Atmos. Chem Phys., 9, 4897-4913, doi:10.5194/acp-9-4897-2009, 2009.

Wang, J., Gille, J. C., Bailey, P. L., Shertz, S., Smith, M., Drummond, J. R., McKernan, E., Tolton, B., Yurganov, L., Jones, N. B., Gore, B., Novelli, P., He, H., McMillan, W. W., Murcray, F., Stephen, T., Pougatchev, N., Reichle, H.G.: The Pre-launch MOPITT Validation Exercise (Pre-MOVE), The Earth Observer, 11, 5-9, 1999.

Yurganov, L. N., Jaffe, D. A., Pullman, E. , Novelli, P. C.: Total column and surface densities of atmospheric carbon monoxide in Alaska, 1995, J. Geophys. Res., 103, 19,337-19,346, 1998.

Yurganov, L. N., Duchatelet, P., Dzhola, A. V., Edwards, D. P., Hase, F., Kramer, I., Mahieu, E., Mellqvist, J., Notholt, J., Novelli, P. C., Rockmann, A., Scheel, H. E., Schneider, M., Schulz, A., Strandberg, A., Sussmann, R., Tanimoto, H., Velazco, V., Drummond, J. R., and Gille, J. C.: Increased Northern Hemispheric carbon monoxide burden in the troposphere in 2002 and 2003 detected from the ground and from space, Atmos. Chem. Phys., 5, 563-573, doi:10.5194/acp-5-563-2005, 2005.

Yurganov, L., McMillan, W., Dzhola, A., Grechko, E, Jones, N., and van der Werf, G.: Global AIRS and MOPITT CO Measurements: Validation, Comparison, and Links to Biomass Burning Variations and Carbon Cycle, J. Geophys. Res., 113, D09301, doi:10.1029/2007JD009229, 2008.

Yurganov, L., McMillan, W., Grechko, E., and Dzhola, A.: Analysis of global and regional CO burdens measured from space between 2000 and 2009 and validated by ground-based solar tracking spectrometers, Atmos. Chem. Phys., 10, 3479-3494, doi:10.5194/acp-10-3479-2010, 2010.

Zander, R., Demoulin, P., Ehhalt, D. H., Schmidt, U., and Rinsland, C. P.: Secular increase of total vertical column abundance of carbon monoxide above Central Europe since 1950, J. Geophys. Res., 94, 11021-11028, 1989.

Zhang, L., Jacob, D. J., Boersma, K. F., Jaffe, D. A., Olson, J. R., Bowman, K. W., Worden, J. R., Thompson, A. M., Avery, M. A., Cohen, R. C., Dibb, J. E., Flock, F. M., Fuelberg, H. E., Huey, L. G., McMillan, W. W., Singh, H. B., and Weinheimer, A. J.: Transpacific transport of ozone pollution and the effect of recent Asian emission increases on air quality in North America: an integrated analysis using satellite, aircraft, ozonesonde, and surface observations, Atmos. Chem. Phys., 8, 6117-6136, doi:10.5194/acp-8-6117-2008, 2008. 